\title{
Efeito de fontes e níveis de selênio sobre parâmetros fisiológicos em frangos de corte
}

[Effect of sources and levels of selenium on physiological traits in broilers]

\author{
F.A. Gomes ${ }^{1}$, A.G. Bertechini ${ }^{2}$, R.L. Dari ${ }^{3}$, J.A.G. Brito ${ }^{4}$, E.J. Fassani ${ }^{2}$, \\ P.B. Rodrigues ${ }^{2}$, L.A. Silva ${ }^{1}$ \\ ${ }^{1}$ Centro Multidisciplinar - UFAC - Cruzeiro do Sul, AC \\ Estrada do Canela fina, km 12, Campus Universitário - 69980-000 - Cruzeiro do Sul, AC \\ ${ }^{2}$ Departamento de Zootecnia - UFLA - Lavras, MG \\ ${ }^{3}$ Biorigin - Lençóis Paulista, SP \\ ${ }^{4}$ Centro de Ciências Agrárias, Ambientais e Biológicas - UFRB - Cruz das Almas, BA
}

\begin{abstract}
RESUMO
Avaliaram-se a retenção aparente, a deposição hepática, tecidual e plasmática, bem como a eficiência da glutationa peroxidase hepática e plasmática em frangos de corte alimentados com diferentes níveis e fontes de selênio. Utilizaram-se 300 pintos machos com 14 dias, submetidos a um esquema fatorial 3x3 + 1 (três níveis de Se - 0,150; 0,300; 0,450ppm, e três fontes comerciais de Se - uma inorgânica e duas orgânicas + um tratamento controle sem suplementação), em DIC. Do primeiro ao $14^{\circ}$ dia de idade período de depleção -, as aves receberam rações basais sem suplementação de selênio. Aos 14 dias, receberam as dietas com selênio, por um período de 14 dias, sendo coletadas as excretas nos últimos quatro dias. A retenção de selênio foi relativamente alta. O uso da fonte orgânica A em níveis crescentes apresentou menor queda na retenção aparente de selênio. As fontes orgânicas participaram mais ativamente nas atividades de tecidos de forma geral, e a fonte inorgânica foi neutralizada no tecido hepático. A eficiência dessa enzima no plasma aumentou linearmente quando se elevaram os níveis dietéticos. Para a fonte inorgânica, não houve mudança nesta eficiência.
\end{abstract}

Palavras-chave: frango de corte, glutationa peroxidase, deposição, retenção, suplementação

\begin{abstract}
We evaluated the apparent retention, the hepatic, tissue and plasmatic deposition as well as the efficiency of the enzyme hepatic and plasmatic Glutathione Peroxidase in broiler chickens fed different sources and levels of selenium. 300 male Cobb- 500 chicks aged 14 days were submitted to a factorial scheme $3 \times 3+1$ (three levels - 0.150; 0.300; 0.450ppm, three commercial sources - one inorganic and two organic + one control treatment without a supplementation) in CRD. The first 14 days of age (depletion period) the birds were fed basal diets without a supplementation of selenium. At 14 days the birds were given the diets with selenium for a period for 14 days, and the excreta collected in the last four days. The work suggested that the selenium retentions were relatively high, due to the use of organic source A at growing levels they presented a lower decrease in apparent retention of selenium. The organic sources participated more actively in the activities of tissues in general and the inorganic source is neutralized in the hepatic tissue. The efficiency of this enzyme in plasma was increased linearly, when we increased dietary levels for the inorganic source there was no change in efficiency.
\end{abstract}

Keywords: broiler, glutathione peroxidase, deposition, retention, supplementation

Recebido em 17 de julho de 2010

Aceito em 6 de abril de 2011

E-mail: gomes.ufla@gmail.com 


\section{INTRODUÇÃO}

A suplementação da ração com microelementos há muito é usada no intuito de atender às necessidades nutricionais das aves, com reflexos positivos sobre o desempenho e a qualidade do produto. Porém, o uso de suplementação de maneira indiscriminada requer alto custo metabólico do organismo da ave, que a predispõe a alterações metabólicas. Pesquisas sobre fontes e níveis de selênio (Se) têm sido realizadas, sendo a forma inorgânica a tradicionalmente utilizada. No entanto, o uso da forma orgânica foi aprovado apenas no ano 2000 pelo Food and Drug Administration (FDA). A partir daí, várias fontes de Se leveduras têm sido testadas para avaliar alguns parâmetros fisiológicos importantes, com resultados interessantes para as aves (Surai, 2000).

O selênio ocorre em todos os tecidos do corpo animal, em concentrações que variam de acordo com as suas necessidades. No momento em que o valor do produto animal enriquecido por Se passa a ser usado como estratégia de melhora nos aspectos produtivos e na qualidade de produtos especiais, o valor do Se orgânico na saúde e na produção animal torna-se especialmente importante. Além disso, a substituição do Se inorgânico pelo Se orgânico tem resultado em uma série de impactos na saúde e no desempenho dos animais, ao promover melhoras na coloração e na qualidade da carcaça (Mahan et al., 1999).

A partir da descoberta da ação do Se em modular a ação da glutationa peroxidase (GSH-Px) e de que sua associação com a vitamina $E$ e outros agentes antioxidantes era capaz de reduzir os efeitos destrutivos das reações peroxidativas nas células vivas, aumentou o número de pesquisas com Se, vit. E e antioxidantes, principalmente depois da descoberta de sua ação sobre radicais livres e peróxidos in vivo, que podem afetar o desempenho dos aves (Suhajda et al., 2000). Os resultados ainda são conflitantes quanto aos efeitos do nível e da fonte sobre parâmetros fisiológicos em frangos de corte. Assim, o objetivo do presente trabalho foi avaliar o efeito de níveis e fontes de Se sobre a deposição de Se hepático, tecidual e plasmático, bem como sobre a eficiência da enzima GSH-Px hepática e plasmática em frangos de corte.

\section{MATERIAL E MÉTODOS}

Foram utilizados 300 pintos machos Cobb-500, com 14 dias de idade, alojados em 60 gaiolas experimentais de metabolismo, onde receberam 10 tratamentos com seis repetições de cinco aves cada. Os tratamentos foram constituídos de suplementação de Se em três níveis - 0,150; 0,300; 0,450ppm, e três fontes, uma inorgânica selenito de sódio - 45,6\% - e duas orgânicas fonte A 2000ppm e fonte B 1000ppm - e um tratamento controle negativo sem suplementação.

A partir do primeiro dia de idade, as aves receberam dieta basal à base de milho e farelo de soja para adaptação, sem suplementação de Se (período de depleção). Aos 14 dias, receberam as dietas para avaliação da suplementação de níveis e fontes de Se, por período de 14 dias, sendo adotado o método de coleta total de excretas. $\mathrm{O}$ período de coleta de excretas ocorreu nos últimos quatro dias dessa fase.

Os dados de análises de Se na dieta e na excreta foram utilizados para a determinação da retenção aparente de Se (RA), sendo calculada como a porcentagem de Se retido em relação ao consumido $\{(\mathrm{RA}=$ (consumo de $\mathrm{Se}-$ excreção de Se)/consumo de Se *100)\}. A partir das equações lineares de retenção, foi determinada a retenção aparente das fontes, considerando-se os coeficientes angulares das retas. Assim, compararam-se as retenções aparentes de fonte inorgânica (100\%) e as fontes orgânicas por meio da estatística Slope Ratio, adaptado, pela seguinte fórmula:

$\mathrm{Y}=\mathrm{a}+\boldsymbol{b} \mathrm{x}_{1}+\boldsymbol{c} \mathrm{x}_{2}+\mathrm{e}$, em que:

$\mathrm{Y}=$ resposta;

a = desempenho mínimo;

b = inclinação (padrão);

c = inclinação (teste);

$\mathrm{e}=$ erro padrão.

A ração basal foi à base de milho e farelo de soja (Tab. 1) suplementada com vitaminas e minerais, com exceção do Se, que foi adicionado de acordo com os tratamentos, e formulada seguindo as recomendações de Rostagno et al. (2005). A composição em Se das dietas encontra-se na Tab. 2. 
Efeito de fontes e níveis de selênio...

Tabela 1. Composição percentual da dieta basal para a fase de 14 a 28 dias de idade dos frangos

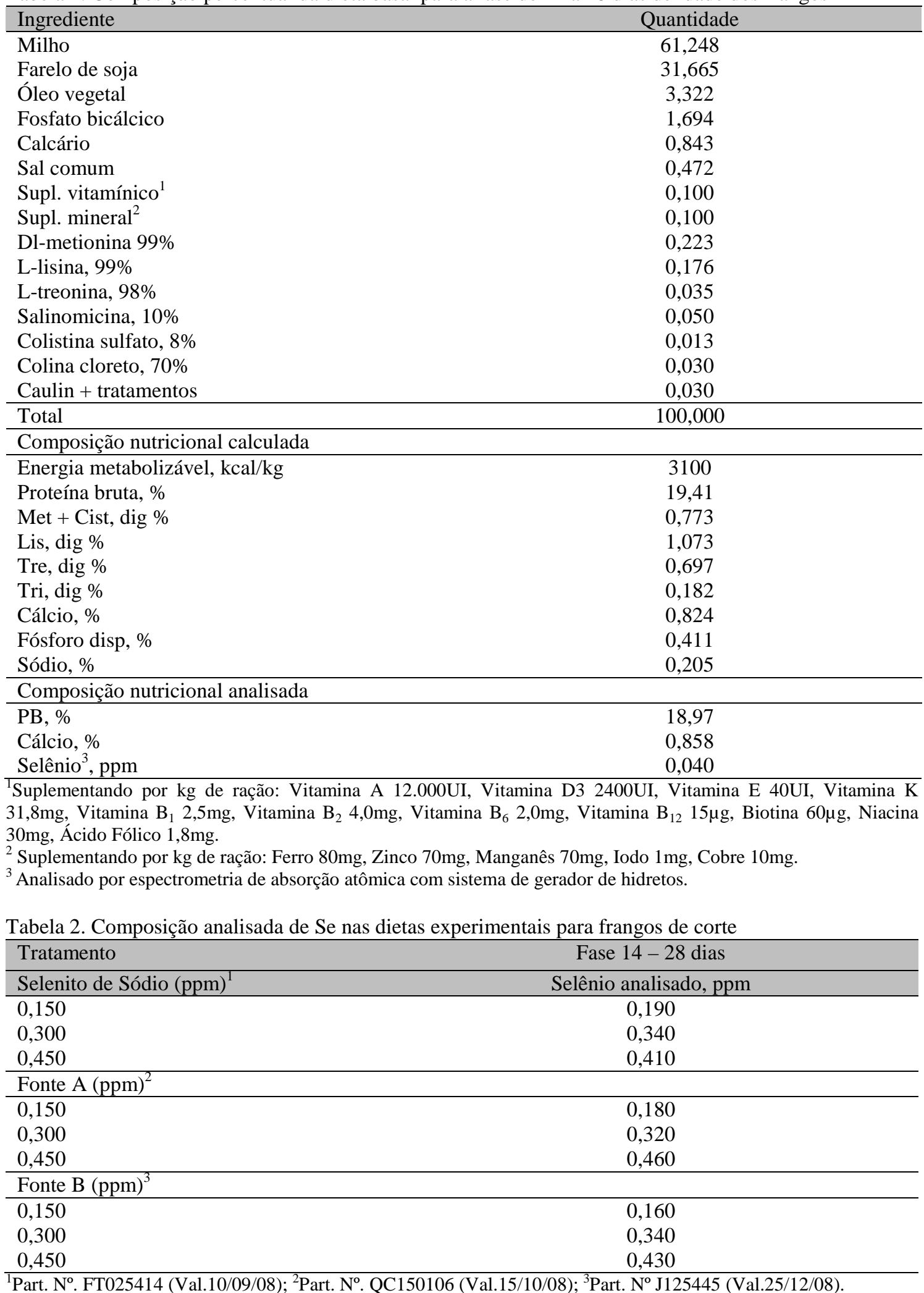


Ao final, realizou-se coleta de sangue por punção cardíaca em tubos vacutainer de $7 \mathrm{~mL}$ com heparina sódica de duas aves por parcela, submetidas a jejum por seis horas, sendo centrifugado imediatamente o material coletado. Em seguida, das aves abatidas por insensibilização elétrica seguida de deslocamento cervical, coletaram-se o fígado e o peito. Todo o material foi pesado e acondicionado em freezer $-20^{\circ} \mathrm{C}$ para posteriores análises de Se e eficiência da GSH-Px.

As análises de conteúdo de Se nas dietas foram feitas por espectrofotometria de absorção atômica equipado para gerador de hidretos. A mesma metodologia foi aplicada para leitura de Se no fígado e peito desossado, após liofilização. Para preparo das amostras de plasma, foi utilizada metodologia para amostras úmidas. A leitura da eficiência da GSH-Px foi realizada seguindo o método descrito por Levander et al. (1983), com pequenas modificações. A eficiência enzimática foi monitorada pela variação da absorbância em espectrofotômetro em função da oxidação do NADPH a 340nm.

O ensaio foi realizado em um esquema fatorial 3x3 +1 em delineamento experimental inteiramente ao acaso.

Os resultados finais foram submetidos à análise de variância utilizando-se 0 pacote computacional Sisvar (Ferreira, 2000), sendo as médias de tratamentos com relação às fontes de Se comparadas pelo teste Tukey, e os níveis de suplementação pelo uso da regressão na análise de variância. Os tratamentos foram comparados em relação ao controle negativo pelo teste de Dunnet. Foi utilizado para todas as comparações o nível de significância de 5\% de probabilidade.

\section{RESULTADOS E DISCUSSÃO}

Os resultados de retenção aparente de Se, de acordo com as fontes estudadas, estão apresentados na Tab. 3. Houve interação $(\mathrm{P}<0,05)$ de fonte de Se versus nível de Se. Para o menor nível de Se suplementar $(0,150 \mathrm{ppm})$, o uso da fonte B resultou em maior retenção aparente, e não foi observada diferença no nível de $0,300 \mathrm{ppm}$ entre as fontes. No maior nível de Se, 0,450ppm, observou-se maior retenção de Se para as fontes orgânicas.
Houve redução linear $(P<0,05)$ na retenção aparente de Se à medida que se elevaram os níveis dietéticos em todas as fontes. Quando analisados os coeficientes angulares de retenção entre as fontes, verificou-se um diferencial na resposta de redução da retenção, diferente entre as fontes estudadas. Assim, notou-se menor velocidade de queda na retenção à medida que se incrementaram os níveis dietéticos para a fonte orgânica A. De acordo com o diferencial do Slope Ratio encontrado e considerando-se o selenito de sódio como $100 \%$ de retenção, o valor relativo para a fonte orgânica A foi $46 \%$ (146) maior, seguido pela fonte B, $25 \%$ (125). Entre as fontes orgânicas estudadas e considerando-se a fonte B como $100 \%$, verifica-se maior retenção relativa para a fonte A, 17\% (117).

Segundo Tapiero (2003), a biodisponibilidade é definida como a proporção de um nutriente ingerido que é retido para utilização em funções fisiológicas normais ou para armazenagem. É sabido que diversos fatores influenciam diretamente a biodisponibilidade do Se; dessa forma, a grande dificuldade de padronização de resultados, quando se comparam estudos que envolvem especialmente microminerais, está diretamente relacionada aos desafios impostos pelos ambientes nos quais os animais estão inseridos, dada a especificidade destes no organismo.

Payne e Southern (2005), ao estudarem diferentes fontes de Se em frangos de corte aos 49 dias, também observaram para a fonte orgânica maior taxa de retenção quando comparada à fonte inorgânica. O mesmo fato foi observado por Yoon et al. (2007).

Houve interação significativa $(\mathrm{P}<0,05)$ de fonte versus nível de Se dietético para deposição hepática. Os teores de Se no fígado foram diferentes segundo a fonte e o nível estudados: maior deposição de Se no fígado das aves foi obtida com o uso da fonte inorgânica, independentemente do nível utilizado. Esse comportamento de acúmulo, considerando-se os aspectos fisiológicos, denota risco em potencial quando se avalia a sobrecarga hepática desse elemento, podendo desencadear processos irreversíveis de intoxicação. $\mathrm{O}$ uso das fontes orgânicas sempre resultou em menor deposição hepática quando comparado ao da inorgânica, resultado que confirma a diminuição do efeito de sobrecarga citado. 
Efeito de fontes e níveis de selênio...

Tabela 3. Retenção aparente e deposição de Se em frangos de corte aos 28 dias alimentados com diferentes fontes e níveis de Se

\begin{tabular}{|c|c|c|c|c|c|}
\hline & Fonto & Nív & iplemen & & \\
\hline & Fonte & 0,150 & 0,300 & 0,450 & Media \\
\hline & Selenito de sódio & $82,64 b$ & $81,34 a$ & $71,59 b^{*}$ & 78,52 \\
\hline$e^{0}$ & Fonte A & $82,13 b$ & $80,11 a$ & 79,98a & 80,74 \\
\hline ஸे & Fonte B & $85,71 \mathrm{a}$ & $81,73 a$ & $79,34 a$ & 82,26 \\
\hline ษั & Média & 83,49 & 81,06 & 76,97 & \\
\hline$\stackrel{\Xi}{\Xi}$ & Controle & 83,51 & & & \\
\hline ప్ర & CV (\%) & 2,05 & & & \\
\hline 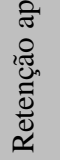 & $\begin{array}{l}\text { Equações de regressão } \\
\text { Selenito de sódio } \\
\text { Fonte A } \\
\text { Fonte B } \\
\end{array}$ & $\begin{array}{l}Y=89,57 \\
Y=82,89 \\
Y=88,63\end{array}$ & $\begin{array}{ll}2 x & \left(r^{2}\right. \\
x & \left(r^{2}=\right. \\
7 x & \left(r^{2}\right.\end{array}$ & & \\
\hline
\end{tabular}

Interação significativa fonte $\mathrm{x}$ nível $(\mathrm{P}<0,05)$.

Valores com letras diferentes, na coluna, diferem entre si pelo teste Tukey $(P<0,05)$.

*Média diferente do controle pelo teste Dunnet $(\mathrm{P}<0,05)$.

\begin{tabular}{|c|c|c|c|c|c|}
\hline \multirow{7}{*}{ 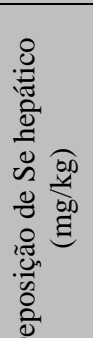 } & Selenito de sódio & $0,722 a$ & $0,962 a^{*}$ & $0,982 a^{*}$ & 0,889 \\
\hline & Fonte A & $0,362 b$ & $0,229 c$ & $0,343 b$ & 0,311 \\
\hline & Fonte B & $0,378 b$ & $0,313 b$ & $0,377 b$ & 0,356 \\
\hline & Média & 0,488 & 0,501 & 0,567 & \\
\hline & Controle & 0,960 & & & \\
\hline & CV (\%) & 6,27 & & & \\
\hline & $\begin{array}{c}\text { Equação de regressão } \\
\text { Selenito de sódio }\end{array}$ & $Y=0,6$ & $5 x$ & & \\
\hline
\end{tabular}

Valores com letras diferentes, na coluna, diferem entre si pelo teste Tukey $(\mathrm{P}<0,05)$.

*Médias iguais ao controle pelo teste Dunnet $(\mathrm{P}>0,05)$.

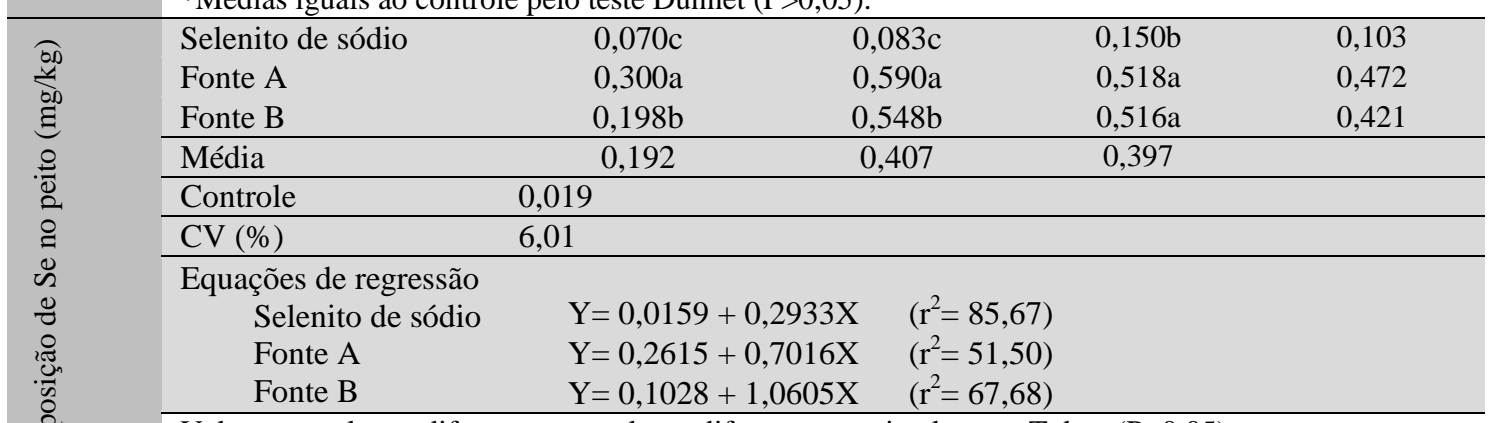

Valores com letras diferentes, na coluna, diferem entre si pelo teste Tukey $(\mathrm{P}<0,05)$.

*Médias diferentes do controle pelo teste Dunnet $(\mathrm{P}<0,05)$.

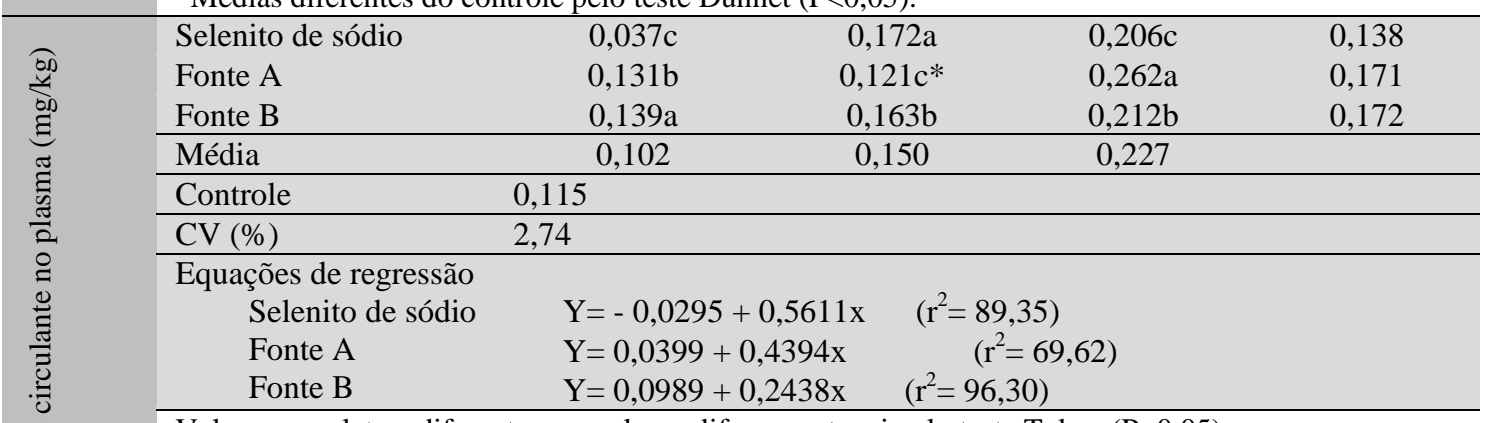

œ $\quad$ Valores com letras diferentes, na coluna, diferem entre si pelo teste Tukey $(\mathrm{P}<0,05)$.

*Média igual ao controle pelo teste Dunnet $(\mathrm{P}>0,05)$. 
Considerando-se as fontes, somente o uso do selenito de sódio resultou em elevação linear $(\mathrm{P}<0,05)$ no nível hepático quando se incrementou o Se na dieta. As fontes orgânicas não apresentaram este efeito, com deposições médias semelhantes, independentemente do nível e da fonte estudados. Quanto à dieta-controle, os resultados indicaram alta deposição hepática, semelhante à fonte inorgânica, podendo ser este um mecanismo metabólico singular do organismo no intuito de resguardar-se diante do não atendimento correto das exigências de Se.

Houve interação significativa $(\mathrm{P}<0,05)$ de fonte versus nível de Se para os teores de Se depositado na carne de peito das aves. A maior deposição de Se na carne de peito foi observada com o uso da fonte orgânica A: para o maior nível de suplementação, as duas fontes orgânicas apresentaram resultados semelhantes. Independentemente do nível dietético, as fontes orgânicas permitiram maior deposição de Se na carne de peito das aves quando comparadas com a fonte inorgânica, resultado condizente com o de Payne e Southern (2005), que observaram deposição tecidual de Se da fonte orgânica duas vezes maior em relação à da fonte inorgânica. $\mathrm{O}$ efeito acumulativo tecidual reflete benefícios consideráveis nos diversos aspectos da cadeia produtiva, como, por exemplo, diminuição de sobrecarga hepática e riscos de intoxicação na criação das aves, e, pós-abate, considerando-se o potencial antioxidante do Se, maior incremento deste elemento na carcaça, o que representa uma estratégia importante na questão de conservação do produto, bem como na repercussão direta da sua qualidade nutricional.

Considerando-se a biodisponibilidade de Se para deposição na carne de peito das aves, a fonte orgânica A apresentou resultados 2,4 vezes maiores do que a fonte inorgânica. Isto significa que a fonte $\mathrm{A}$ apresenta biodisponibilidade relativa de $242 \%$ em relação à de selenito de sódio (100\%) para deposição tecidual no peito das aves.

Verifica-se que a etapa limitante na determinação da retenção de Se da dieta não parece ser a absorção, mas sim a conversão para a forma biologicamente ativa nos tecidos, afirmação esta feita pela observação dos complexos de Se orgânico com maior potencial de retenção. Esta afirmação é condizente com os estudos feitos por Suhajda et al. (2000).

Também houve interação significativa $(\mathrm{P}<0,05)$ de fonte versus nível de Se plasmático. Os maiores teores de Se no plasma foram observados para a fonte orgânica B com 0,150ppm, fonte inorgânica selenito de sódio com 0,300ppm e fonte orgânica A com 0,450ppm. O aumento do nível de Se suplementar resultou em aumento linear $(\mathrm{P}<0,05)$ na concentração plasmática. Comparando-se as fontes, verificaram-se maiores coeficientes angulares de resposta para as fontes orgânicas em relação à inorgânica, resultados que revelam a preferencial destinação do Se orgânico para o metabolismo extra-hepático.

Yoon et al. (2007), ao estudarem respostas fisiológicas de frangos de corte aos 42 dias, suplementados com diferentes fontes e níveis de Se, verificaram maior concentração plasmática desse mineral nas aves que ingeriram fontes orgânicas. Resultado semelhante foi observado por Payne e Southern (2005), quando estudaram frangos de corte aos 49 dias.

A eficiência da GSH-Px hepática, de acordo com a fonte de Se e o nível de suplementação, está apresentada na Tab. 4. Houve interação significativa $(\mathrm{P}<0,05)$ de fonte versus nível de Se. Na suplementação com 0,150ppm, a maior eficiência na atividade da GSH-Px foi observada para a fonte orgânica B. Coincidentemente, o fígado foi o tecido de maior deposição hepática de Se para a fonte inorgânica. Este fato confirma o efeito da fonte inorgânica voltada mais para o metabolismo hepático. Os resultados para os níveis intermediário e maior de Se mostraram maior eficiência para GSH-Px na fonte inorgânica. Quando se elevou o nível de Se suplementar, somente as fontes orgânicas responderam ao elevarem a atividade da enzima. Estes resultados indicam que o Se inorgânico incrementou a atividade da GSH-Px hepática até a suplementação de 0,150ppm. Comparando-se as duas fontes orgânicas (BfonteA/bfonteB*100), verifica-se que a fonte orgânica $A$ apresentou incremento médio e maior que a fonte $\mathrm{B}$, da ordem de $3 \%$. Estes resultados indicam que o Se orgânico permanece maior tempo na circulação sanguínea quando comparado ao da fonte inorgânica, que apresenta deposição hepática maior. 
Efeito de fontes e níveis de selênio...

Tabela 4. Eficiência da enzima GSH-Px em frangos de corte aos 28 dias alimentados com diferentes fontes e níveis de Se

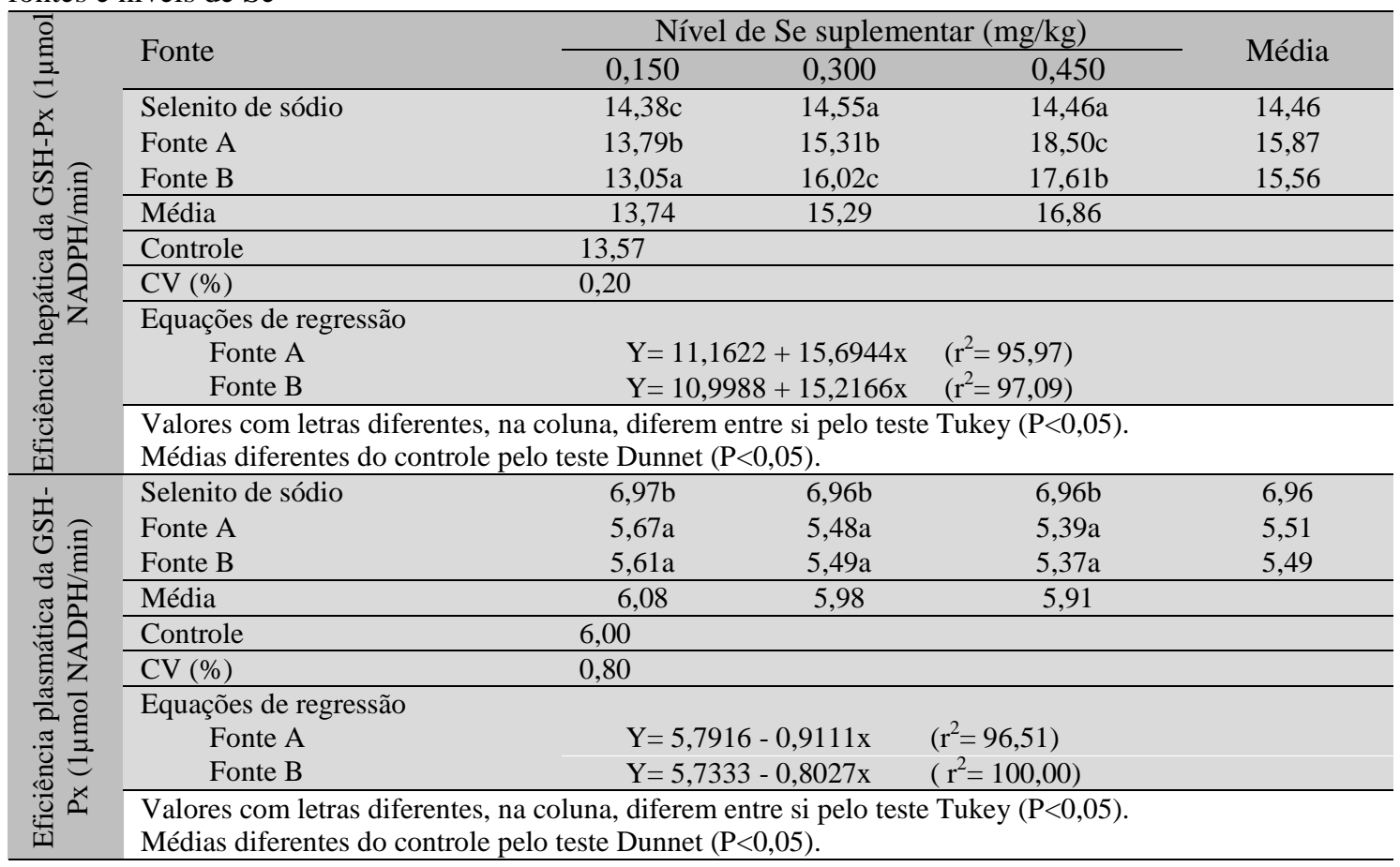

Ali et al. (1997), Mahan et al. (1999) e Moreira et al. (2001) observaram ligeiras tendências de as fontes inorgânicas promoverem maior eficiência na viabilização da GSH-Px hepática em relação às fontes orgânicas. No entanto, a explicação para tal fato ainda não é clara, existindo apenas a suposição em razão da maior eficiência da fonte inorgânica em promover efeito acumulativo de Se hepático - que é uma condição de risco -, mantendo o Se por mais tempo no fígado e, por consequência, não suprindo corretamente as exigências. Isto foi observado neste trabalho quando se elevaram os níveis de Se orgânico, mantendo a fonte inorgânica maior eficiência desta enzima no fígado. Quando se avaliou o nível de 0,150ppm, a fonte orgânica proporcionou melhor eficiência. A interpretação, neste estudo, de acordo com metodologia de Levander et al. (1983), utilizada por Yoon et al. (2007), foi feita em razão da quantidade/eficiência da enzima necessária para oxidar $1 \mu \mathrm{mol}$ NADPH/min.

Na GSH-Px hepática, foi encontrada menor eficiência à medida que se elevou o nível para as fontes orgânicas, podendo ser justificada por ser este órgão o primeiro depositário, pós-absorção, de Se no organismo. O acúmulo desse elemento condiciona à maior síntese enzimática que, em função do estado fisiológico, poderá ou não ser utilizada pelo organismo. A partir daí, o Se orgânico foi mais bem distribuído pelo organismo, com efeito benéfico acumulativo nos tecidos, enquanto o Se inorgânico tendeu a manter-se no fígado, destinando-se aos fins citados.

Houve interação significativa de fonte versus nível de Se para eficiência da GSH-Px plasmática estudadas para a atividade dessa enzima $(\mathrm{P}<0,05)$. $\mathrm{O}$ uso do selenito de sódio, como fonte de Se, possibilitou a menor $(\mathrm{P}<0,05)$ eficiência da GSH-Px no plasma dos frangos de corte e constante à medida que se elevou a suplementação dietética. As fontes orgânicas comportaram-se de maneira semelhante $(\mathrm{P}>0,05)$, ocorrendo aumentos lineares $(\mathrm{P}<0,05)$ dessa eficiência à medida que se elevaram a suplementação dietética de Se, resultados que corroboram com Yoon et al. (2007), que observaram aumento linear na eficiência da enzima quando se aumentou o nível de suplementação em frangos de corte aos 42 dias.

Em animais em que a exigência de Se é atendida e, por consequência, os aspectos imunitários, 
bioquímicos (radicais livres) e metabólicos estão em equilíbrio/homeostase, observa-se atividade de GSH-Px mais eficiente, visto o organismo entender desnecessários níveis mais elevados de Se no plasma, pois é sabido que toda enzima possui substrato-dependência; ou seja, neste caso não seriam justificáveis altos níveis em razão de condições fisiológicas de homeostase.

Nos tratamentos controle e fonte inorgânica, a menor eficiência da glutationa peroxidase plasmática é justificada em razão da maior demanda dessa enzima para oxidação do NADPH, mecanismo necessário para sua ativação para o combate direto aos substratos metabólicos residuais gerados pelo não e/ou ineficiente atendimento correto das exigências, visto os animais se encontrarem em condições de não homeostase. Neste contexto, salienta-se também a maior quantidade de Se acumulado e direcionado para o metabolismo hepático.

Segundo Ali et al. (1997), a exigência de Se para frangos de corte, no NRC (Nutrient..., 1994), é de $0,150 \mathrm{ppm}$, o que seria suficiente para otimizar a atividade da glutationa peroxidase até os 21 dias de idade. Esta afirmação está de acordo com os resultados obtidos neste experimento, em que, para o aumento do nível de suplementação da fonte orgânica, manteve-se a mesma eficiência para a enzima no plasma sanguíneo. Com relação à fonte inorgânica, o nível de 0,150ppm também foi suficiente e satisfatório em manter melhor eficiência na atividade dessa enzima no fígado, podendo ser explicado, ainda, pelo maior acúmulo de Se neste órgão quando comparado ao das fontes orgânicas.

\section{CONCLUSÕES}

O uso das fontes orgânicas suplementares de Se em substituição a fontes inorgânicas, em frangos de corte, mostraram-se melhores quanto à retenção aparente, e à deposição tecidual e plasmática desse mineral. A maior eficiência da glutationa peroxidase plasmática ficou evidenciada com o uso suplementar de Se orgânico, o que fornece melhor idéia da importante atividade dessa enzima nos demais tecidos corpóreos.

\section{REFERÊNCIAS BIBLIOGRÁFICAS}

ALI, J.; LEDOUX, D.R.; BERMUDEZ, A.J. et al. Selenium requirement of broilers fed corn-soybean meal diets from day 1 to 21. Poult. Sci., v.76, p.58, 1997.

FERREIRA, D.F. Sistema para análise de variância - SISVAR - Lavras: UFLA, 2000.

LEVANDER, O.A.; DE LOACH, D.P.; MORRIS, V.C. et al. Platelet glutathione peroxidase activity as an index of selenium status in rats. J. Nutr., v.113, p.55-63, 1983.

MAHAN, D.C.; CLINE, T.R.; RICHERT, B. Effect of dietary levels of selenium-enriched yeast and sodium selenite as selenium sources fed to growing finishing pigs on performance, tissue selenium, serum Glutathione Peroxidase activity, carcass characteristics and loin quality. J. Anim. Sci., v.77, p.2172-2179, 1999.

MOREIRA, J.; SANTOS, C.D.; ABREU, C.M.P. et al. Efeito de fontes e níveis de selênio na atividade enzimática da glutationa peroxidase e no desempenho de frangos de corte. Cienc. Agrotecnol., v.25, p.661-666, 2001.

NUTRIENT requirements of poultry. 9.ed., rev. Washington: National Academy, 1994.

PAYNE, R.L.; SOUTHERN, L.L. Comparison of inorganic and organic selenium sources for broilers. Poult. Sci., v.84, p.898-902, 2005.

ROSTAGNO, H.S.; ALBINO, L.F.T.; DONZELE, J.L. et al. Tabela brasileira para aves e suínos: composição de alimentos e exigências nutricionais. Viçosa: UFV, 2005. 186p.

SUHAJDA, A.; HEGÓCZKI, J.; JANZSÓ, B. et al. Preparation of selenium yeasts I. Preparation of selenium-enriched Saccharomyles cerevisiae. J. Trace Elem. Med. Biol., v.14, p.43-47, 2000.

SURAI, P.F. Effect of selenium and vitamin E content of the maternal diet on the antioxidant system of the yolk and the developing chick. $\mathrm{Br}$. Poult. Sci., v.41, p.235-243, 2000.

TAPIERO, H. The antioxidant role of selenium and seleno-compounds. Biomedic. Pharmacother., v.57, p.134-144, 2003.

YOON, I.; WERNER, T.M.; BUTLER, J.M. Effect of source and concentration of selenium on growth performance and selenium retention in broiler chickens. Poult. Sci., v.86, p.727-730, 2007. 